\title{
DE QUÉ HABLAMOS CUANDO DECIMOS QUE LA RENTA BÁSICA ES (O NO) JUSTA. SOBRE LIBERALISMOS Y REPUBLICANISMOS'
}

\author{
WHAT WE MEAN WHEN WE SAY BASIC INCOME IS (OR IS \\ NOT) JUST: ON LIBERALISMS AND REPUBLICANISMS
}

Daniel Raventós

Recibido: junio de 2011

Universidad de Barcelona

Aceptado: septiembre de 2011

Palabras clave: republicanismo, liberalismo, neutralidad, Robespierre, poder de negociación, clase obrera, feminismo.

Keywords: republicanism, liberalism, neutrality, Robespierre, bargaining power, working class, feminism.

Resumen: En este articulo se explica la distinción entre el liberalismo político y el liberalismo académico. Se desarrolla una triple distinción del republicanismo: el histórico (democrático y oligárquico) y el neorepublicanismo académico. Se explica alguna confusión que surge cuando se abordan cuestiones tan básicas y habituales en la literatura académica como son la neutralidad y la virtud. Y se realiza una justificación republicano-democrática de la renta básica. Especialmente, se aborda desde esta perspectiva lo que la renta básica podría significar para la clase trabajadora y las mujeres.

Abstract: The difference between political liberalism and academic liberalism is explained in this article, which then distinguishes three strands of republicanism: historic (democratic and oligarchic) republicanism and academic neo-republicanism. Explanation is offered regarding some of the confusion that arises with approaches in academic literature to such basic and standard notions as neutrality and virtue, after which a democratic-republican justification of basic income is offered with particular attention to what a basic income might mean for the working class and women. 
Una de las primeras preguntas que surgen al tratar de la Renta Básica es si es justa. Hay quien formula la pregunta de forma diferente: ¿Es ética la Renta Básica? Alguna distinción debe hacerse al respecto. Admitamos que cada persona tiene su propia moral. Unas morales pueden ser muy poco pensadas y otras pueden llegar a ser muy sofisticadas. La ética está muy relacionada con la moral, pero no se trata de lo mismo. La ética puede definirse como «el análisis crítico de los contenidos o reglas morales y la elaboración de criterios racionales para elegir entre morales alternativas» (Mosterín, 2006: 370). ${ }^{2}$ Teniendo esta distinción presente, creo que, en relación con la Renta Básica, es más ajustado hablar de justicia que de ética, aunque no es infrecuente la utilización de los dos términos indistintamente. $Y$ de la justicia o de la falta de ella de una determinada propuesta social tratan las llamadas teorías de la justicia. Preguntarnos por la justicia de la propuesta de la Renta Básica resulta muy relevante. Una medida social que fuera política o económicamente viable poco interesante resultaría si no fuera justa.

\section{Un mapa abreviado sobre liberalismos y otro de más amplio sobre republicanismos}

Pero evidentemente, "sociedad justa», no es un concepto sobre el que haya más consenso académico y político que el que pueda haber ante conceptos y realidades como "sociedad libre», «sociedad democrática» o similares. Un cierto mapa de las distintas teorías o concepciones de la justicia que han ensayado la fundamentación de la Renta Básica es necesario. Las principales concepciones de la justicia son las liberales y las republicanas. Liberalismo y republicanismo son palabras que no tienen un único sentido y por esta razón será necesario esbozar un cierto mapa.

Empecemos por el liberalismo. De las distintas divisiones que podríamos hacer, una es particularmente útil: la que distingue entre liberalismo político y liberalismo académico. El liberalismo político nace en las Cortes españolas de Cádiz (1812) y luego se difunde por el mundo (Domènech, 2009: 7). Tiene pues dos siglos casi exactos. Así que anacronismo es presentar, entre otros, a John Locke, Adam Smith o Immanuel Kant como liberales (algunos sitúan también a ¡Maximilien Robespierre! como liberal). ${ }^{3}$ El primero murió en 1704 , el segundo en 1790 y el tercero en 1804 (y Robespierre en 1794). Difícilmente podían ser partidarios o componentes de algo que no se había inventado. Corresponde a los historiadores continuar analizando el papel histórico del liberalismo, así como su vieja enemistad con la democracia, la libertad y la igualdad. ${ }^{4}$

El liberalismo académico es una amalgama en la que pueden entrar autores que políticamente se situarían muy a la derecha, otros en el centro y, finalmente, otros en la izquierda más o menos moderada. Dentro del liberalismo académico pueden encontrarse muchas subespecies: libertariano, igualitarista, propietarista... ${ }^{5}$ ¿Qué tienen en común estas teorías de la justicia académicas 
liberales? Según uno de los destacados liberales defensores de la Renta Básica, lo que tienen en común es «una concepción que prohíbe toda jerarquía de las diversas concepciones de la vida buena que puedan encontrarse en la sociedad» (Van Parijs, 1991: 244). Retomaremos la cuestión.

Algunas distinciones sobre el republicanismo. Me limitaré a tres: el republicanismo histórico (que a su vez se divide en oligárquico y democrático) y el neorepublicanismo académico. ${ }^{6}$

Nombres que se han asociado al republicanismo antiguo son, en la versión democrático-plebeya, los de Efialtes (?-461 a.n.e.), Pericles (495-429 a.n.e.), Protágoras (485-411 a.n.e.) o Demócrito (470/460-370/360 a.n.e.); en la versión antidemocrática, los de Aristóteles (384322 a.n.e.) o Cicerón (106-43 a.n.e.). Estas dos grandes variantes aparecen también en el mundo moderno. La variante democrática aspira a la universalización de la libertad republicana y a la consiguiente inclusión ciudadana de la mayoría pobre, e incluso al gobierno de esa mayoría de pobres. La antidemocrática pretende la exclusión de la vida civil y política de quienes viven por sus manos y el monopolio del poder político por parte de los ricos propietarios. Nombres que deben relacionarse con el renacimiento moderno del republicanismo son, entre otros, los de Marsiglio de Padua (? -1342), Maquiavelo (1469-1527), cierto Montesquieu (1689-1755), John Locke (1632-1704), Rousseau (17121778), Kant (1724-1804), Adam Smith (1723-1790), Jefferson (1743-1826), Madison (1751-1836), Robes-pierre (1758-1794) y Marx (1818-1883).
La tradición republicana democrática hay que buscarla en la Atenas posterior al 461 antes de nuestra era. Allá triunfó el programa democrático revolucionario del mundo clásico que podemos resumir en: 1) la redistribución de la tierra; 2) la supresión de la esclavitud por deudas; y 3) el sufragio universal acompañado de remuneración suficiente (misthón) para los cargos públicos electos. Importante es señalar que democracia significaba para los griegos gobierno de los pobres (libres). ${ }^{7}$ Recuérdese que la democracia ática llegó, después del -461, a conceder igual libertad de palabra en el ágora (isegoria) a las mujeres y a los esclavos.

La tradición republicana oligárquica (y antidemocrática) se negó, por distintos motivos, a universalizarla (Domènech, 2004). El republicanismo democrático y no democrático (u oligárquico) comparten la perspectiva de que la «propiedad» (los medios de existencia) es necesaria para la libertad. Sin embargo, así como el republicanismo no democrático sostiene que los no propietarios deben ser excluidos de la ciudadanía, el republicanismo democrático defiende que deben asegurarse los medios para que toda la ciudadanía sea materialmente independiente.

El neorepublicanismo académico debido, entre otros, a Quentin Skinner, J.G.A. Pocock y, quizás especialmente, a Philip Pettit, diluye la relación entre propiedad y libertad republicana. También queda diluida la relación entre democracia y propiedad. Pettit razona la libertad republicana como un concepto disposicional, en contraste con la libertad negativa liberal de pura no interferencia. 
La libertad republicana sería ausencia de dominación, de interferencia arbitraria de otros particulares (o del Estado). Aquí hay una diferencia fundamental puesto que, para el republicanismo histórico, la fuente fundamental de vulnerabilidad e interferibilidad arbitraria es la ausencia de independencia material. Si se descuida esa raíz institucional fundamental de la capacidad de dominar, entonces la «dominación» se diluye y desinstitucionaliza, y caen también bajo ella aspectos de las relaciones humanas que el republicanismo histórico jamás habría considerado pertinentes políticamente, por ejemplo: el engaño podría llegar a ser una forma de «dominación», pues quien engaña interfiere arbitrariamente en la vida del engañado.

La conexión entre propiedad y libertad republicana a la que se aludía un poco más arriba es especialmente relevante para un republicano democrático emblemático, Robespierre.

\section{Un ejemplo de relación propiedad-libertad- democracia: la concepción de Robespierre}

Si algún autor ha sido escarnecido y calumniado inmediatamente después de su muerte por parte de la derecha, éste ha sido Maximilien Robespierre (17581794). Que lo haya sido por intelectuales, políticos y propagandistas de la derecha política es algo completamente normal y hasta predecible. Que la izquierda no haya tenido mucha mayor simpatía por este político y pensador ya no resulta tan normal ni predecible. ${ }^{8}$
Robespierre fue la figura central de la Revolución Francesa. Con su muerte, esta revolución dio rápidamente paso a la reacción, que poco después desembocaría en el Imperio napoleónico. Pero, evidentemente, no nos interesa aquí la figura de este revolucionario más allá de su aportación al republicanismo. Por ello, de los 10 volúmenes que reúnen sus obras y discursos, publicados a partir de 1910, solamente nos importará la parte que más directamente está relacionada con la propiedad, las grandes desigualdades sociales, la libertad y la existencia social. ${ }^{9}$

Aunque que sea muy brevemente, creo que será útil mencionar que, para Robespierre, las partes principales de la ciudad son las que están constituidas por ricos y por pobres, como para Aristóteles, aunque los separen dos milenios. Robespierre lo expresa así: «Sin duda, Francia está dividida en dos partes, el pueblo y la aristocracia» (discurso del 2-2-1790).

¿Qué es la propiedad para Robespierre? En el discurso a la convención del 24-41793, el revolucionario francés ofrece una larga reflexión como respuesta a esta pregunta:

«Preguntad a aquel comerciante de carne humana qué es la propiedad. Os dirá, mostrándoos un ataúd, al que denomina barco, donde ha encajonado y herrado a hombres que parecían vivos: 'Ésas son mis propiedades, las he comprado a tanto por cabeza.' Interrogad a ese gentilhombre, que tiene tierras y vasallos, o que cree que el mundo se ha trastornado desde que ya no los tiene. Os dará ideas sobre la propiedad prácticamente iguales. 
Interrogad a los augustos miembros de la dinastía capeta; os dirán que la más sagrada de todas las propiedades es, sin discusión, el derecho hereditario, del que han gozado desde la antigüedad, el derecho a oprimir, a envilecer y ahogar legal y monárquicamente a su antojo a los veinticinco millones de hombres que vivían en el territorio de Francia».

Esta descarnada y vivísima descripción de la propiedad sirve de telón de fondo de la concepción normativa que Robes-pierre ofrece de la misma, esto es, de lo que según él debe ser la propiedad para que sea socialmente justa. Dice al respecto, en forma de artículos, en el mismo discurso:

«Art. 1. La propiedad es el derecho que tiene cada ciudadano de disfrutar y disponer de la porción de bienes que le garantiza la ley.

Art. 2. El derecho a la propiedad está limitado, como todos los demás, por la obligación de respetar los derechos ajenos.

Art. 3. No puede perjudicar ni la seguridad, ni la libertad, ni la existencia, ni la propiedad de nuestros semejantes.

Art. 4. Toda posesión, todo tráfico que viole ese principio es ilícito e inmoral.»

La propiedad, para Robespierre, debe estar limitada y no debe perjudicar ni a la libertad, ni a la existencia. Si la propiedad no cumple con al menos estos requisitos, resulta ilícita e inmoral. En el discurso a la Convención del 2-12-1792, declara: "¿Por qué no deben las leyes detener la mano homicida del monopolista, del mismo modo que lo hacen con el asesino ordinario?»

La propiedad y la libertad están íntimamente relacionadas. En otro momento, dirigiéndose a los diputados, dirá:
«Al definir la libertad, el primero de los bienes del hombre, como el más sagrado de los derechos que hereda de la naturaleza, habéis dicho con razón que tenía como límite los derechos ajenos. ¿Por qué no habéis aplicado este principio a la propiedad, que es una institución social; como si las leyes eternas de la naturaleza fuesen menos inviolables que las convenciones de los hombres? Habéis multiplicado los artículos para asegurar la mayor libertad en el ejercicio de la propiedad, y no habéis dicho nada para determinar su carácter legítimo». («Acerca de la Declaración de los Derechos del Hombre y el Ciudadano», discurso del 24-4-1793).

La insistencia en la idea de que no toda propiedad es legítima recorre la obra de Robespierre. Si atenta contra la libertad, la propiedad no es legítima. Y la gran desigualdad social que crean las enormes y desproporcionadas fortunas, atenta contra la libertad. Para Robespierre, la gran desigualdad económica es la raíz de la destrucción de la libertad. La gran desigualdad, dirá, es «la fuente de todos los males». En el discurso del 5-41791, reprende a los legisladores y les lanza: "Legisladores, no habéis hecho nada por la libertad si vuestras leyes no tienden a disminuir, mediante formas dulces y eficaces, la extrema desigualdad de las fortunas. » $Y$ el 24-4-1793 incide en la misma idea: "Realmente no hacía falta una revolución para explicar al universo que la extrema desproporción de las fortunas es el origen de muchos males y de muchos crímenes».

Interesante es señalar cómo en un discurso tan temprano, de abril de 1791, Robespierre ya señala que los propieta- 
rios no son los únicos que tienen derecho a llamarse ciudadanos: "Los ricos... han pretendido que sólo los propietarios eran dignos del título de ciudadano. Han llamado interés general a su interés particular, y para asegurar el éxito de esta pretensión, se han apoderado de toda la potencia social».

Casi como conclusión de la exposición de su concepción de la propiedad, de la libertad y de las grandes desigualdades sociales, Robespierre hace reiteradas muestras de una profunda convicción relativa a la necesidad de que la sociedad garantice la existencia material de la ciudadanía. Aquí las citas directas son muy abundantes. Las mejores correspondan quizás al último año y medio de la corta vida del revolucionario francés (recuérdese que Robespierre vivió solamente 36 años).

Una sociedad que no garantice la existencia material ciudadana no es justa y, por ello mismo, no merece continuar. En el ya citado discurso del 24-4-1793 declara: "La sociedad está obligada a procurar la subsistencia de todos sus miembros...». Y añade un poco después: "Las ayudas necesarias para la indigencia son una deuda del rico hacia el pobre. Incumbe a la ley determinar la manera como esa deuda debe saldarse.»Porque la sociedad y, a veces ya más directamente los gobiernos, son los responsables del hambre, de la pobreza, de la miseria: "La miseria de los ciudadanos no es otra cosa que el crimen de los gobiernos» (discurso del 10-5-1793). Pero si hay una cita repetida por mérito propio acerca de las obligaciones de la sociedad con respecto a la existencia material ciudadana es ésta, que co- rresponde al discurso sobre las subsistencias del 2-12-1792:

«¿Cuál es el primer fin de la sociedad? Mantener los derechos imprescriptibles del hombre. ¿Cuál es el primero de esos derechos? El de existir. La primera ley social es, pues, la que asegura a todos los miembros de la sociedad los medios de existir; todas las demás se subordinan a ésta; la propiedad no ha sido instituida, ni ha sido garantizada, sino para cimentar aquella ley; es por lo pronto para vivir que se tienen propiedades. Y no es verdad que la propiedad pueda jamás estar en oposición con la subsistencia de los hombres.»

Compárese la conciencia que tiene Robespierre de las fatales consecuencias para la libertad que comportan las grandes desigualdades con estos dos discursos realizados poquísimos meses después de su muerte a manos de la reacción termidoriana. El primero corresponde a Boissy d'Anglas (1756-1826):

«Tenemos que ser gobernados por los mejores; los mejores son los más instruidos y los más interesados en el mantenimiento de las leyes. Ahora bien; descontadas algunas excepciones, no hallaréis hombres así sino entre quienes gozan de alguna propiedad, los cuales adhieren al país en la que ésta se halla, a las leyes que la protegen, a la tranquilidad que la conserva, y deben a esa propiedad y a la holgura que ella proporciona la educación que los ha hecho capaces de discutir, con sagacidad y precisión, sobre las ventajas y los inconvenientes de las leyes que determinan la suerte de la patria (...) Un país gobernado por los propietarios está en el orden social; uno gobernado por los no propietarios [la democracia] es el estado de naturaleza». 
El segundo discurso tiene por autor a Dupont de Nemours (1739-1817). Decía el diputado termidoriano:

«Es evidente que los propietarios, sin cuyo permiso nadie podría en el país conseguir alojamiento y manutención, son los ciudadanos por excelencia. Ellos son los soberanos por la gracia de Dios, de la naturaleza, de su trabajo, de sus inversiones y del trabajo y de las inversiones de sus antepasados. ${ }^{10}$

Dupont de Nemours fue un termidoriano famoso que fundó la compañía que lleva su nombre, que se convirtió en una poderosa multinacional química. Boissy d'Anglas fue un diputado también termidoriano.

\section{La concepción republicana de la libertad}

Una convicción es común, más allá de las diferencias que puedan tener en otros terrenos, a todos los pensadores y políticos republicanos desde los tiempos de Aristóteles (y aún anteriores) hasta el republicanismo democrático actual, pasando, claro está, por Robespierre:

1) Ser libre significa no depender de otro particular para vivir, no ser arbitrariamente interferible por este otro particular; quien depende de otro para vivir, no es libre. Quien no tiene asegurado el «derecho a la existencia» por carecer de propiedad o por otros medios $^{11}$ no es sujeto de derecho propio -sui iuris-, vive a merced de otros, y no es capaz de cultivar -y menos ejercitar- la virtud ciudadana; y ello es así porque esta dependencia con res- pecto a otro particular lo convierte en un sujeto de derecho ajeno: un alieni iuris, un «alienado».

2) La libertad republicana puede alcanzar a muchos (democracia plebeya, como defienden los republicanos democráticos) o a pocos (oligarquía plutocrática, como defendieron los republicanos oligárquicos y, por tanto, antidemocráticos), pero siempre está fundada en la propiedad y en la independencia material que de ella se deriva. Y esta libertad no podría mantenerse si la propiedad estuviera tan desigual y polarizadamente distribuida, que unos pocos particulares pudieran desafiar a la república y luchar con éxito contra la ciudadanía para imponer su concepción del bien público. Cuando la propiedad está muy desigualmente repartida, poco espacio hay, si alguno, para la libertad del resto, de los que están privados de ella. ${ }^{12}$

Podemos sintetizar la concepción republicana de la libertad de la siguiente forma. $\mathrm{X}$ es republicanamente libre si:

a) tiene una existencia social autónoma $y$, en consecuencia, puede vivir por sus propios medios (normalmente su propiedad), con lo que no depende de otro particular para vivir;

b) nadie puede interferir arbitrariamente (es decir, ilícitamente o ilegalmente) en el ámbito de existencia social autónoma de X (en su propiedad);

Con lo que:

c) la república puede interferir lícitamente en el ámbito de existencia social autónoma de $\mathrm{X}$, siempre que $\mathrm{X}$ esté en relación política de parigualdad con to- 
dos los demás ciudadanos libres de la república, con igual capacidad que ellos para gobernar y ser gobernado;

d) cualquier interferencia (de un particular o del conjunto de la república) en el ámbito de existencia social privada de $X$ que dañe ese ámbito hasta hacerle perder a X su autonomía social, poniéndolo a merced de terceros, es ilícita;

e) la república está obligada a interferir en el ámbito de existencia social privada de $\mathrm{X}$, si ese ámbito privado capacita a $X$ para disputar con posibilidades de éxito a la república el derecho de ésta a definir el bien público. Es decir, la república debe garantizar a toda la ciudadanía la libertad republicana.

Finalmente:

f) X está afianzado en su libertad cívicopolítica por un núcleo duro -más o menos grande- de derechos constitutivos (no puramente instrumentales) que nadie puede arrebatarle, ni puede él mismo alienar (vender o donar) a voluntad, sin perder su condición de ciudadano libre. ${ }^{13}$

Para la tradición republicana, el conjunto de oportunidades de $\mathrm{X}$ está claramente delimitado por aquellas propiedades que posibilitan que disponga de una existencia social autónoma. No se trata de un conjunto de oportunidades cualquiera, sino de éste en concreto. La ciudadanía plena no es posible sin independencia material o sin un «control» sobre el propio conjunto de oportunidades así concretado. La tradición republicana considera que la libertad política y el ejercicio de la ciudadanía son incompatibles con las relaciones de dominación mediante las cuales los propietarios y ricos ejercen dominium sobre aquellos que, por no ser completamente libres, están sujetos a todo tipo de interferencias; ya sea en el ámbito de la vida doméstica o en el de las relaciones jurídicas propias de la vida civil como los contratos de trabajo o de compra y venta de bienes materiales.

Hasta aquí, todas las concepciones en común de republicanos democráticos y oligárquicos. Pero desde aquí republicanos democráticos y republicanos oligárquicos se separan. Para los primeros, de lo que se trata es de diseñar mecanismos que hagan posible esta libertad, que hagan posible esta existencia material para toda la ciudadanía, para toda la población. En cambio, los republicanos oligárquicos trataron siempre de excluir de la vida política activa a los que no eran sui iuris. Kant, por ejemplo, era de la opinión de que los que son puestos bajo la tutela de otros individuos no poseen independencia civil. No la poseen los menores de edad, las mujeres y los sirvientes, porque no pueden conservar por sí mismos su existencia en cuanto a sustento y protección; tampoco los jornaleros, ni todos aquellos que no pueden poner públicamente en venta el producto de su trabajo y dependen de contratos o arreglos meramente privados de esclavitud temporaria, que brotan de la voluntad unilateral del sui iuris. ${ }^{14}$

En la tradición republicana, la independencia que confiere la propiedad no es un asunto de mero interés propio privado. Es, por el contrario, de la mayor importancia política, tanto para el ejercicio de la libertad como para la realiza- 
ción del autogobierno republicano, pues tener una base material asegurada es indispensable para la propia independencia y competencia políticas.

\section{La virtud y la neutralidad republicanas}

No son infrecuentes los análisis en los que se asegura que el republicanismo está comprometido con la virtud de los ciudadanos, lo que lo convierte en una tradición moralmente perfeccionista, razón por la cual resulta incompatible con un estado que sea neutral con respecto a las distintas concepciones del bien. Por consiguiente, se sigue asegurando en esta habitual secuencia, el republicanismo es una doctrina políticamente sectaria e incompatible con la tolerancia entre las distintas concepciones del bien.

Empecemos por la virtud. La tradición histórica republicana no se ha planteado nunca la cuestión de la virtud de forma a-institucional, esto es, como un problema de mera psicología moral. Ya desde Aristóteles, toda referencia a la virtud ha ido acompañada de consideraciones institucionales y relativas a las bases sociales y materiales que hacen (o no) posible esta virtud. La virtud tiene, evidentemente, una dimensión psicológico-moral, pero el republicanismo siempre ha acompañado el análisis de esta dimensión con la afirmación de que sólo sobre el suelo de una existencia socio-material, aquélla puede brotar. Aristóteles niega que el pobre libre tenga una base autónoma de existencia, pues no dispone de propiedad. Esta carencia de base autónoma de existencia impide que pueda ser libre y, por esa razón, Aristóteles defiende que los pobres libres sean privados de los derechos políticos. A partir de esta constatación, la virtud republicana no tiene nada que ver con el perfeccionismo moral, ni apela a una concepción de la buena vida aislada de las instituciones sociales. Todo lo contrario: la tradición republicana defiende que cuando la ciudadanía tiene garantizada por la república una base material para su existencia social autónoma, puede desarrollar una capacidad para autogobernarse en su vida privada. Y, además, tal garantía de una base material para la existencia social autónoma de los individuos posibilita que estos desarrollen su capacidad para la actividad pública. Claro que esta base material también puede empujar a algunos ciudadanos a atiborrarse de cerveza y de comida colesterólica mientras ven los programas televisivos más infames. Los defensores del republicanismo no niegan esta eventualidad; lo que afirman es que esta base material da la posibilidad (en mucho mayor grado que la situación en la que viven quienes carecen de ella) para desarrollar la virtud cívica, que no es otra cosa -repito la formulación anterior- que la capacidad para autogobernarse en la vida privada y, de ahí, llegar a la vida pública ejerciendo plenamente su condición de ciudadanos, esto es, de individuos materialmente independientes.

Sigamos ahora con la neutralidad del Estado. Académicamente, por neutralidad del estado se entiende que éste no tome partido por ninguna concepción de 
la vida buena. Las concepciones de la vida buena deben quedar circunscritas a la elección personal. Se admite que las teorías liberales de la justicia son neutrales respecto a las distintas concepciones particulares de la vida buena. Había citado más arriba a Philippe Van Parijs para exponer su opinión sobre lo que tienen en común las distintas teorías académicas de la justicia liberales. Según este autor, lo que tienen todas las teorías académicas liberales de la justicia es «una concepción que prohíbe toda jerarquía de las diversas concepciones de la vida buena que puedan encontrarse en la sociedad» (Van Parijs, 1991: 244). Este rasgo distintivo de las teorías académicas liberales de la justicia es un lugar más o menos común, pero no dice gran cosa. Las teorías de la justicia que optan por la defensa y la recompensa de una concepción determinada de la vida buena son perfeccionistas. $\mathrm{O}$, dicho con otras palabras, «un estado se define como 'neutral' en la medida en que no se inmiscuye, por ningún medio, en la esfera privada de los individuos, esto es, en la (mal) llamada15 'sociedad civil'»(Casassas, 2010: 131). Así está establecido en las discusiones académicas. Para la tradición histórica republicana el punto realmente interesante es otro. Según el republicanismo, no hay duda de que el estado debe mantenerse respetuoso con respecto a las distintas concepciones de la buena vida que puedan abrazar los ciudadanos. «[L]a tesis de la neutralidad del estado es un invento característicamente republicano, al menos tan viejo como Pericles» (Bertomeu y Domènech, 2006). De hecho, al republicanismo histórico le ha interesado algo, a mi entender, mucho más sugestivo y amplio. Me estoy refiriendo a la «obligatoria» interferencia abierta por parte del estado para destruir (o limitar) la base económica e institucional de personas, empresas o cualquier otra agrupación particular que amenacen con disputar con éxito al estado republicano su derecho a determinar lo que es de pública utilidad. Y esto quiere decir algo tan sencillo como lo siguiente. Imaginemos un poder privado tan desarrollado que pueda permitirse imponer su voluntad (su concepción del bien privado) al estado. Lo que comportará que la neutralidad de éste quede arrasada de facto. Lo que comportará, a su vez, que una gran parte de la población, dependiendo obviamente de cada caso, quede afectada por esta concepción del bien privado. La concepción republicana de la neutralidad del estado apunta, precisamente, a la necesidad de que éste intervenga para evitar esta imposición y para preservar la libertad ${ }^{16}$ de la ciudadanía toda. Pueden ponerse tres ejemplos que dejan bien claro el punto que estoy sosteniendo. Los dos primeros ejemplos son de actuación republicana positiva y provienen de la primera mitad del siglo XX: «la República de Weimar luchaba por la neutralidad del estado cuando peleó -y sucumbió- contra los grandes Kartells de la industria privada alemana que financiaron la subida de Hitler al poder; la República norteamericana luchó -sin éxito- por la neutralidad del estado cuando trató de someter, con la ley antimonopolios de 1937, a lo que Roose-velt llamaba los 'monarcas económicos'; etc» (Bertomeu y Domènech, 2006). El tercer ejemplo, es de rabiosa actualidad y es un ejemplo a contrario: el saqueo a 
la gran mayoría de la población por parte de los grandes grupos de especuladores y financieros. En palabras del gran economista Michael Hudson (2010): «para que pueda gobernar el capital financiero primero deben saquearse a fondo las economías». Resulta aterrador para la libertad de millones de personas cómo los grupos de banqueros y especuladores (bajo el eufemismo de los «mercados») han impuesto a los gobiernos elegidos por sufragio universal su concepción del bien privado. Es decir, chantajeando y presionando a los gobiernos para obligarles a imponer tremebundos ataques a las condiciones de vida y trabajo de las clases trabajadoras, pretextando que el déficit público era insostenible. Y siendo estas medidas servilmente aceptadas y aplicadas por dichos gobiernos, con particular celeridad por el del Reino de España a partir de mayo de 2010, sea dicho de pasada.

El problema de la neutralidad del estado, para la tradición republicana, no tiene que ver con la pregunta relativa a si se debe respetar una concepción de la buena vida que, por ejemplo, asocie el bien a la consagración de la lectura repetida de las obras de H.P. Lovecraft o de Edgar Allan Poe combinada con la audición casi ininterrumpida de las composiciones de John Lennon o de Nikolai Andreyevich Rimsky-Korsakov, o a si tal concepción debe ser respetada por el estado o no. Que la debe respetar, por supuesto. El problema es si, por ejemplo, la existencia material de una persona o de un buen grupo de ellas debe depender de los planes de inversión de una transnacional o de un poderoso grupo de especuladores. $\mathrm{O}$ si los recursos energéticos de países enteros deben estar a disposición de los consejos de administración de algunas grandes empresas. O si los dogmas de algunas iglesias pueden llevar a la expropiación de la existencia material de determinadas personas. En estos casos, nos hallamos ante planes de vida -ante nociones de la vida buena- que tiene la facultad de erosionar la base material de terceros, por lo que atentan a su libertad. Un estado republicanamente neutral debe imposibilitar que se den este tipo de situaciones.

\section{5. ¿Cómo puede justificar la concepción republicana de la libertad a la propuesta de la Renta Básica? Comentario sobre las mujeres y la clase trabajadora}

La independencia, la existencia material, la base autónoma (son expresiones aquí perfectamente permutables) que confiere la propiedad es condición indispensable para el ejercicio de la libertad. De ahí la idea sugerida por parte de los defensores republicanos de la Renta Básica: «universalizar la propiedad». Universalizar la propiedad debe entenderse de forma metafórica. Nadie está pensando seriamente en repartir la propiedad de un país dado, o del mundo, entre los habitantes del país en cuestión, en el primer caso, o del mundo entero, en el segundo. Universalizar la propiedad debe ser entendido aquí de forma equivalente a garantizar a todos la existencia material (Casassas y Raventós, 2007). 
La instauración de una Renta Básica de una cantidad igual o superior al umbral de la pobreza de la zona donde se implantase, supondría una independencia socioeconómica, una base autónoma de existencia mucho mayor que la actual para buena parte de la ciudadanía, sobre todo para los sectores de la ciudadanía más vulnerables y más dominados en las sociedades actuales (buena parte de los trabajadores asalariados, pobres en general, parados, mujeres, etc.). En definitiva, la introducción de una Renta Básica haría que la libertad republicana, para algunos grupos de vulnerabilidad, viese ensanchadas sus posibilidades. Por grupo de vulnerabilidad se entiende aquí aquel conjunto de personas que tienen en común el ser susceptibles de interferencia arbitraria en su existencia social por parte de otros conjuntos de personas o de alguna persona en particular.

En primer lugar, me referiré a este gran y heterogéneo grupo que forman las mujeres. Hay una evidencia: todas las mujeres no se hallan en la misma situación social. Pero tampoco parece muy discutible la afirmación de que una Renta Básica conferiría a una buena parte de este gran y heterogéneo grupo de vulnerabilidad social que forman las mujeres una independencia económica de la que actualmente no disponen. ${ }^{17} \mathrm{Si}$ bien la Renta Básica, por definición, es independiente de la contribución en trabajo que se pueda realizar, creo necesario señalar aquí que, pese a que no reciban ninguna remuneración monetaria a cambio, la mayor parte de las mujeres trabaja. ${ }^{18}$

Presento a continuación algunas de las razones que avalan republicanamente la
Renta Básica en relación con las mujeres:

a) En primer lugar, cabe señalar que la Renta Básica da una respuesta contundente a la necesidad de que la política social se adapte a los cambios en los modos de convivencia, en especial al incremento de familias monoparentales encabezadas por mujeres.

b) En segundo lugar, al constituir una asignación individual, la Renta Básica mejoraría la situación económica de muchas mujeres casadas con hombres o que viven en pareja de otro sexo ${ }^{19}$, sobre todo la de aquéllas que se hallan en los estratos más empobrecidos de la sociedad. Efectivamente, buena parte de los subsidios condicionados existentes tienen como unidad de asignación la familia. Normalmente, el perceptor y administrador es el cabeza de familia -los hombres, mayoritariamente-, de forma que a las personas que ocupan la posición más débil -las mujeres, mayoritariamente- se les priva del acceso y del control del uso de tales ingresos. Al decir de Pateman (2006: 115): «Una Renta Básica es importante para el feminismo y la democratización precisamente porque está pagada no a los hogares sino a los individuos como ciudadanos». ${ }^{20}$

c) En tercer lugar, la independencia económica que la Renta Básica posibilitaría puede hacer de ella una suerte de «contrapoder» doméstico capaz de modificar las relaciones de dominación entre sexos y de incrementar la fuerza de negociación de muchas mujeres dentro del hogar, especialmente la de aquéllas que dependen 
del marido o que perciben ingresos muy bajos por estar empleadas de modo discontinuo o a tiempo parcial.

d) En cuarto lugar, como muchas autoras feministas han mostrado a lo largo de las últimas décadas, el sistema de seguridad social de los países ricos fue erigido asumiendo que las mujeres eran económico-dependientes de sus maridos. Lo que comportaba que los beneficios conseguidos de la seguridad social lo eran por las contribuciones de sus maridos, no por su condición de ciudadanas. En un contexto de creciente cuestionamiento del estereotipo male breadwinner, no resulta caprichoso suponer que las elecciones sobre el trabajo doméstico podrían ser tomadas de un modo mucho más consensuado de lo que mayoritariamente lo es hoy.

Pero, junto a estos cuatro puntos, puede hacerse una reflexión de mayor envergadura sobre el papel de la Renta Básica para favorecer republicanamente la existencia material de las mujeres. Esta reflexión ha sido sugerida por Carole Pateman. Resumidamente, puede ser expuesta de la siguiente manera. Muchos de los problemas relacionados con la cuestión de la reciprocidad en la filosofía política de los últimos años hacen referencia únicamente a las actividades que tienen que ver directamente con el trabajo remunerado. ¿Es violada la reciprocidad cuando una persona recibe una asignación incondicional ${ }^{21}$, la Renta Básica en nuestro caso, incluso cuando esta persona está en perfectas condiciones para trabajar remunerada-mente, y simplemente no quiere hacerlo, incurriendo clamorosamente en el caso del gorrón (free-rider)? Pateman opina que ésta es una forma muy limitada de analizar el problema, puesto que se enfoca tomando en consideración solamente el trabajo con remuneración. Queda ignorado, en cambio, el problema de la reciprocidad (y del free-rider) que se produce en un tipo de trabajo no remunerado, pero muy amplio y que mayoritariamente desempeñan las mujeres: el doméstico. Y esto, a mi entender, enlaza con un problema de mucha mayor envergadura que es motivo de atención por parte del republicanismo democrático: la situación de dependencia por la que históricamente, incluso después de la abolición de las leyes del Antiguo Régimen, las mujeres han estado sujetas a los hombres. Me valdré de un caso histórica para hacer más ligera la exposición del punto exacto al que quiero llegar. En 1792, Robespierre abolió la distinción entre ciudadanos activos y pasivos, es decir, entre los ciudadanos que podían tener derecho al voto y los que no -dicha distinción se establecía en función de la cantidad de impuestos que los individuos podían pagar-. Dicho de otro modo, ciudadano activo era aquel que tenía determinado nivel de riqueza, mientras que ciudadano pasivo era aquel que no llegaba a este nivel. Todo ello, obviamente, referido a los hombres. Las mujeres quedaban patriarcalmente excluidas por su condición de sujetos dependientes de los varones. ${ }^{22}$ Aquí es donde enlazo con la preocupación de Pateman reproducida un poco más arriba. La Renta Básica, por su carácter universal para toda la ciudadanía y residencia acreditada, no va dirigida ni a hogares ni a personas con características específicas (ser hom- 
bres, por ejemplo). Por esta razón, la Renta Básica puede ser un medio eficaz para asegurar la base autónoma de una parte importante de mujeres que, hoy por hoy, dependen, para su existencia material, de sus maridos o amantes.

En segundo lugar, voy a referirme a lo que de interés tiene para el republicanismo la instauración de una Renta Básica para la clase trabajadora, otro de los grupos de vulnerabilidad a los que me refería más arriba.

Empecemos por un punto especialmente interesante y que han estudiado algunos autores: ${ }^{23}$ la desmercantilización de la fuerza de trabajo y el poder de negociación de los trabajadores que una Renta Básica comportaría. En las economías capitalistas, las personas que no disponen de la propiedad de tierras o de medios de producción deben vender su fuerza de trabajo en el mercado laboral a un propietario de tierras o de medios de producción, llamado empleador, para poder adquirir todos aquellos medios que permitirán su subsistencia. Esta situación ha recibido el nombre de «mercantilización de la fuerza de trabajo» (a veces, directamente, «mercantilización del trabajo»), puesto que esta capacidad de trabajar de los que no tienen otra propiedad que les permita eludir el trabajo asalariado es tratada como una mercancía. Los trabajadores pueden tener sus necesidades de subsistencia cubiertas fuera del mercado mediante algunos mecanismos de provisión social. En este caso, su fuerza de trabajo es desmercantilizada. Podemos así hablar de grados distintos de mercantilización (y de desmercantili-zación) de la fuerza de trabajo. La Renta Básica tendría un efecto importante como herramienta para la desmercantili-zación de la fuerza de trabajo, siempre que fuera al menos de una cantidad que permitiera «la libertad de no ser empleado» (Pateman, 2006: 104).

Pero la Renta Básica también tendría otro interesante efecto sobre la clase trabajadora que, desde la perspectiva republicana, resulta particularmente interesante: el aumento del poder de negociación que lograrían los miembros de la clase trabajadora frente al empresario o empleador.

La seguridad en los ingresos que la garantía de una Renta Básica comportaría, impediría que los trabajadores se viesen impelidos a aceptar una oferta de trabajo de cualquier condición. Desde el momento en que su salida del mercado de trabajo resultara practicable, supondría una posición negociadora (o de resistencia, como a veces se ha llamado) mucho mayor que la que los trabajadores poseen ahora. No es lo mismo llevar las negociaciones laborales al límite de la ruptura cuando se cuenta, como es el caso de los empresarios, con la posibilidad real de reemplazar a los trabajadores contendientes por maquinaria o por trabajadores actualmente en paro -los que engrosan las filas del otrora llamado "ejército industrial de reserva-, ${ }^{24}$ que hacerlo a sabiendas de que la subsistencia depende de forma directa, y prácticamente exclusiva, de las retribuciones obtenidas de los individuos sentados en el otro lado de la mesa de negociación, como les ocurre a los trabajadores y trabajadoras. La relación laboral bajo el capitalismo es claramente asimétrica. Una Renta Básica haría prac- 
ticable no sólo la posibilidad de negarse de forma efectiva y convincente a aceptar situaciones no deseadas por parte de muchos trabajadores, sino también plantearse formas alternativas de organización del trabajo que permitieran aspirar a grados de realización personal más elevados.

Además, la Renta Básica supondría, en caso de huelga, una especie de caja de resistencia incondicional e inagotable cuyos efectos para el fortalecimiento del poder de negociación de los trabajadores son fáciles de discernir. Efectivamente, el hecho de que en caso de conflicto huelguístico los trabajadores dispusieran de una Renta Básica permitiría afrontar las huelgas de una forma mucho menos insegura que en la actualidad: a día de hoy, dependiendo de los días de huelga, los salarios pueden llegar a reducirse de forma difícilmente soportable si, como acostumbra a ocurrir para la inmensa mayoría de la clase trabajadora, no se dispone de otros recursos.

Al fin y al cabo, la propuesta de la Renta Básica es una opción de política económica. Muy diferente a la que se viene practicando a lo largo de las últimas 4 décadas y, en especial, a partir del estallido de la crisis económica en el año 2007. Y más en especial aún desde las medidas que a partir de mayo de 2010 se pusieron en marcha por parte de muchos gobiernos, entre ellos el del Reino de España. Entre estas medidas de política económica practicada en los últimos 40 años podemos enumerar: rebajar los impuestos de los más ricos, facilitar legalmente a las empresas el despido de los trabajadores así como contratarlos de forma más barata, per- mitir las operaciones económicas altamente especulativas, distribuir la renta de los más pobres a los más ricos, permitir la existencia de los paraísos fiscales, recortar el gasto público dedicado a sanidad y educación, y otras medidas que se han practicado del mismo tono. La opción por la Renta Básica es una opción de política económica de todo punto diferente, por concepto y por orientación social, a las anteriores.

\section{Bibliografía citada:}

Añón, M.J. y Miravet, P. (2004): «El derecho a un ingreso y la cuestión social de las mujeres europeas», en Discriminación y diferencia, J. Martínez Ridaura y Mariano J. Aznar (coords.), Valencia: Tirant lo Blanc.

Bambrick, L. (2006): «Wollstonecraft's Dilemma: Is a Citizen's Income the Answer?», Citizen's Income Newsletter, 2, pp. 3-10.

Bertomeu, M.J. (2005a): «Las raíces republicanas del mundo moderno: en torno a Kant», en M.J. Bertomeu, A. Domènech y $A$. de Francisco (eds.), Republicanismo y democracia. Buenos Aires: Miño y Dávila Editores.

Bertomeu, M.J. (2005b): «Republicanismo y propiedad», El Viejo Topo 207.

Bertomeu, M.J. y Domènech, A. (2005): «El republicanismo y la crisis del rawlsismo metodológico (Nota sobre método y substancia normativa en el debate republicano)», Isegoría, 33, pp. 51-75.

Bosc, Y., Gauthier, F. y Wahich, S. (editores) (2005): Por la felicidad y por la libertad (discursos de Robespierre), Barcelona: el Viejo Topo. 
Casassas, D. (2010): La ciudad en Ilamas. La vigencia del republicanismo comercial de Adam Smith, Barcelona: Montsesinos.

Casassas, D. y Loewe, G. (2001): «Renta Básica y fuerza negociadora de los trabajadores», en Raventós, D. (coord.), La Renta Básica. Por una ciudadanía más libre, más igualitaria y más fraterna. Barcelona: Ariel.

Casassas, D. y Raventós, D. (2007): «Propiedad y libertad republicana: La Renta Básica como derecho de existencia para el mundo contemporáneo», Sin Permiso, 2, pp. 35-69.

Casassas, D. y Raventós, D. (editores) (2011): La renta básica en la era de las grandes desigualdades, Barcelona: Montesinos.

Domènech, A. (2004): El eclipse de la fraternidad, Barcelona: Crítica.

Domènech, A. (2006): «Azarosas élites bajo palabra de honor», Sin Permiso, 1, pp. 263-276.

Domènech, A. (2009): «Dominación, derecho, propiedad y economía política popular. Un ejercicio de historia de los conceptos», Sin Permiso, disponible en $<$ http://www.sinpermiso.info/articulos/ficheros/dominacion.pdf>.

Domènech, A. y Raventós, D. (2004): "La Renta Básica de Ciudadanía y las poblaciones trabajadoras del primer mundo», Le Monde diplomatique (ed. española), 105.

Domènech, A. y Raventós, D. (2008): «Propiedad y libertad republicana: una aproximación institucional a la Renta Básica», Sin Permiso, 4, pp. 193-199.

Hudson, M. (2010): «El pueblo contra los banqueros. Hoy Grecia, mañana Es- tados Unidos», Sin Permiso, disponible en <http://www.sinpermiso.info/textos/ index. php?id=3327>.

Kant, I. (1989): Metafísica de las costumbres, Madrid: Tecnos.

Lefebvre, G. (1957): Les Thermidoriens - Le Directoire, París: Armand Colin.

Lo Vuolo, R., Raventós, D. y Yanes, P. (2010): «El Ingreso Ciudadano-Renta Básica ante la crisis económica y los ataques a los derechos sociales y laborales», Sin Permiso, disponible en <http:/ /www. sinpermiso.info/textos/index.php? $\mathrm{id}=3550$ > .

Lo Vuolo, R., Raventós, D. y Yanes, P. (2011): "La crisis económica, los subsidios condicionados y el Ingreso Ciudadano-Renta Básica» en D. Casassas y D. Raventós (eds.), La renta básica en la era de las grandes desigualdades, Barcelona: Montesinos.

Mathiez, A. (1988): Études sur Robespierre, París: Messidor /Editions sociales.

Mosterín, J. (2006): La naturaleza humana, Pozuelo de Alarcón: Gran Austral. Mundó, J. (2006): «Locke y Aristóteles. Isomorfismos en la tradición filosóficopolítica republicana», en Bertomeu, M.J.; A. Velasco (eds.), La vigencia del republicanismo. México: Universidad Nacional Autónoma de México.

Parker, H. (1993): Citizen's Income and Women, BIRG Discussion Paper 2. Londres: Citizen's Income.

Pateman, C. (2003): «Freedom and Democratizacion: Why Basic Income is to be Preferred to Basic Capital», en Keith Dowding, J. de Wispelaere y Stuart White (eds.) The Ethics of Stakeholding. Basingstoke: Palgrave. 
Pateman, C. (2006): "Democratizing Citizenship: Some Advantages of a Basic Income», en B. Ackerman, A. Alstott and P. Van Parijs (eds.), Redesigning Distribution, London-New York: Verso.

Rand, A. (1967): Capitalism: The Unknown Ideal, New York: Signet.

Raventós, D. (2002): «Detrás de la desigualdad hay un problema de libertad o «los que viven con permiso de otros», $E l$ valor de la palabra- Hitzaren Bailoa, 2, pp. 78-102.

Raventós, D. (2007): Las condiciones materiales de la libertad, Barcelona: El Viejo Topo. La edición en inglés fue publicada por Pluto Press también en 2007 con el título: Basic Income: The Material Conditions of Freedom.

Raventós, D. y Casassas, D. (2003): «La Renta Básica y el poder de negociación de 'los que viven con permiso de otros'». Revista internacional de sociología, 34, pp. 187-201.

Robeyns, I. (2001): «An Income of One's Own», Gender and Development, vol. 9, pp. 82-89.

Robeyns, I. (2008): «Introduction: Revisiting the Feminism and Basic
Income Debate,» Basic Income Studies: vol. 3: iss. 3, article 3.

Van Parijs, P. (1991): Qu'est-ce qu'une société juste? París: Seuil.

Van Parijs, P. (2006): «Basic Income versus Stakeholder Grants: Some afterthoughts on how best to redesign distribution» en B. Ackerman, A. Alstott y P. Van Parijs (eds.), Redesigning Distribution, London-New York: Verso.

White, S. (2003a): The Civic Minimum, Oxford: Clarendon Press.

White, S. (2003b): «Fair reciprocity and basic income», en A. Reeve y A. Williams (Edts.), Real Libertarianism Assessed: Political Theory after Van Parijs, Houndmills: Palgrave Macmillan.

White, S. (2007): «The Republican Case for Basic Income: A Plea for Difficulty,» Basic Income Studies: vol. 2: iss. 2, article 13.

Wright, E. O. (2006): «Basic Income as a Socialist Project», Basic Income Studies, vol. 1: iss. 1, article 12.

Xarxa Renda Bàsica (2006): Preguntes i respostes sobre la renda bàsica. Barcelona: XRB-RRB.

\section{Notas}

\footnotetext{
${ }^{1}$ Este texto, con leves modificaciones y actualizaciones, es un capítulo del libro de Casassas y Raventós (2011).

2 El autor añade: «Hay morales religiosas, pero no existe (sería un oxímoron) una ética religiosa. Algunos llamados comités de ética a veces son meros voceros de una determinada moral religiosa y deberían llamarse comités de moral católica, por ejemplo. Así se entenderían mejor sus remilgos ante entidades tan poco merecedoras de consideración moral como las células madre o las blástulas de las que proceden».
}

3 Para John Locke, cfr. Mundó (2006); para Adam Smith, cfr. Casassas (2010); para Immanuel Kant, cfr. Bertomeu (2005); para Robespierre, cfr. Raventós (2007).

${ }^{4}$ Un análisis muy documentado puede leerse en Domènech (2004). «Soy antidemócrata, porque soy liberal», dirá el poeta Matthew Arnold (1822-1888), citado en Domènech (2006: 270).

5 Para un repaso de cómo distintas teorías liberales académicas justifican la Renta Básica: Raventós (2007). 
${ }^{6}$ Véase para una ampliación de este punto Domènech y Raventós (2008).

${ }^{7}$ De forma clara para Aristóteles: Pol., 1279b 39 - 1280a 1-3; 1291b 8-13. Véase, para una ampliación de la concepción aristotélica, Domènech (2004: 53-58) y Raventós (2007: 63-68).

${ }^{8}$ Es indispensable, para una evaluación de Robespierre, toda la obra del historiador Albert Mathiez (1874-1932), si bien un buen y relativamente breve compendio puede encontrarse en Mathiez (1988).

${ }^{9}$ Bosc, Gauthier y Wahnich (2005) ofrecen una selección muy útil de tales textos y discursos. En francés, puede consultarse: <http:/ /membres.lycos.fr/discours/discours.htm>.

${ }^{10}$ Ambas citas son de Lefebvre (1957: 199200). Pueden hallarse también en Domènech (2004: 92).

${ }^{11}$ De ahí la gran importancia de la instauración en la democracia ática postefiáltica del misthón o salario público, la remuneración de los cargos electos.

12 Para una ampliación de ese punto, véase Bertomeu (2005b).

13 Bertomeu y Domènech (2005).

${ }^{14}$ Kant (1989).

15 Mal llamada «sociedad civil» porque para el republicanismo, la sociedad civil es propiamente la asociación de ciudadanos libres e iguales (iguales porque son recíprocamente libres). "La distinción entre lo -civil- y -lo político-», aunque tiene un interesante antecedente en Montesquieu, no se convierte en un lugar común hasta el siglo XIX, con la eclosión del liberalismo antirrepublicano y antidemocrático» (Domènech, 2009: 7).

${ }^{16}$ Compárese la concepción republicana de la libertad con la de la novelista preferida de Alan Greenspan, la ultraliberal Ayn Rand: «La libertad, en un contexto político, significa libertad frente al gobierno, frente a [su] coerción. No significa libertad frente al terrateniente, o libertad frente al empresario, o libertad frente a las leyes de la naturaleza, que distan de proporcionar a los hombres una prosperidad automática; significa libertad frente al poder coercitivo del estado, iy nada más!» (Rand, 1967: 192). Agradezco a Jordi
Mundó el haberme puesto sobre la pista de tan reveladoras palabras.

17 Parker (1993); Robeyns (2001 y 2008); Añón y Miravet (2004); Pateman (2003, 2006); XRB- RRB (2006); Bambrick (2006).

18 Existen tres tipos de trabajo: con remuneración, doméstico y voluntario. Esta clasificación en tres tipos de trabajo cumple bien con los criterios formales de una buena clasificación. Sea $X$ el trabajo remunerado, $Y$ el trabajo doméstico y $Z$ el trabajo voluntario:

1) Ningún subconjunto de la partición queda vacío: $X \neq \varnothing ; Y \neq \varnothing ; Z \neq \varnothing ; 2)$ La partición es exhaustiva: ningún elemento de $X$, de $Y$ o de $Z$ queda fuera de la partición; y 3) La partición es excluyente: los miembros de $X$, de $Y$ y de $Z$ no pertenece a más de un subconjunto.

Si bien el tercer criterio debería relajarse: la mayoría de mujeres realizan trabajo doméstico y una parte también realiza trabajos de los otros dos tipos.

${ }^{19}$ En caso de mujeres casadas o que viven en pareja con otras mujeres, el razonamiento no sería exactamente el mismo, como resulta obvio.

20 Subrayado en el original.

${ }^{21}$ Como sugiere White (2003a, 2003b y 2007).

22 Robespierre mismo, al final de su vida, parece comprender «la inexorable lógica con la que la fraternité -como programa democrático de plena y universal civilización de la vida social, económica, familiar y política- tenía que traer consigo la cumplida emancipación de las mujeres» (Domènech, 2004: 91).

23 Entre otros: Raventós (2007), Pateman (2006); Wright (2006); Van Parijs (2006); XRB-RRB (2006); Domènech y Raventós (2004); Raventós y Casassas (2003); Raventós (2002); Casassas y Loewe (2001).

24 Un ejército de trabajadores cada vez más numeroso desde que en agosto de 2007 estalló la crisis económica de la que no hemos salido a mediados de 2011 ni hay perspectivas de salir a corto plazo. En Lo Vuolo, Raventós y Yanes (2010) se aborda el papel de una Renta Básica en una situación de crisis económica como la actual. Véase también Lo Vuolo, Raventós y Yanes (2011). 